\title{
Jogo, mimese e infância: o papel do jogar infantil nos processos de construção do self
}

\author{
Tamara Grigorowitschs
}

Universidade de São Paulo, Programa de Pós-Graduação em Sociologia

\author{
Mas quando um poeta moderno diz que para cada um \\ existe uma imagem em cuja contemplação o mundo \\ inteiro submerge, para quantas pessoas essa imagem não \\ se levanta de uma velha caixa de brinquedos? \\ Walter Benjamim, (1913-1932) 2002, p. 102
}

Quais são os possíveis significados do jogo infantil? O que diferencia o jogar adulto do jogar na infância? O jogo desempenha um papel na construção da identidade na infância e na inserção das crianças no mundo social? Que papel é esse?

O intuito deste artigo é apresentar uma abordagem sociológica dessas questões que revele a importância do jogo nos processos de socialização infantil e de formação do self na infância. Lanço mão de autores clássicos que refletiram a respeito dos processos de formação do self no jogo infantil, como Walter Benjamin ([1929-1936] 1985, [1932-1933] 1987, [1913-1932] 2002) e George Herbert Mead ([1934] 1952), e de alguns de seus intérpretes contemporâneos, como Gunter Gebauer e Christoph Wulf $(1992,1998)$ autores que organizaram essa discussão em torno do conceito de mimese. Na segunda parte do artigo, como forma de enriquecer o debate teórico sobre o assunto, analiso duas imagens presentes em Infância em Berlim por volta de 1900, de Walter Benjamin, que retratam de forma autobiográfica o papel do jogo para a formação do self na infância.

\section{Jogo infantil como problema sociológico}

O engajamento das crianças no jogo parece ser algo universal em qualquer período histórico do qual se tenha informações; já a percepção do jogo infantil como uma ação específica e digna de investigação possui origens variadas. Em Platão aparecem as primeiras observações de que se tem conhecimento sobre o jogar infantil e suas relações com a vida em sociedade, nas quais o jogo desempenharia um papel "pedagógico" (Fass, 2003; Runkel, 1986). Muito mais tarde, ao final do século XVIII, o pensamento de extração rousseauniana passa a valorizar a espontaneidade do jogar infantil, concebendo a criança como portadora "da verdade", na medida em que suas atitudes, do ponto de vista de Jean-Jacques Rousseau ([1762] 1966), pareciam situar-se mais próximas da natureza do que do domínio da razão. Ao final século XIX, Karl Gross (1895) enfatizou a dimensão biológica do jogo infantil, considerado uma necessidade de qualquer animal jovem. No âmbito da educação, Friedrich W. Fröbel ([1891] 2001), também na mesma época, incorporou 
essas duas últimas correntes e passou a privilegiar uma educação "natural" tendo como base o jogo, mas deixando em segundo plano sua dimensão social (Brougère, 1999). Com base nesses contextos sóciohistóricos, o jogo infantil passou a ser valorizado como um fim em si mesmo, mas também como possuidor de um papel fundamental na educação.

O termo jogo abarca elementos muito diversos e por vezes desarticulados entre si; desse modo, é impossível incluir todas as formas de jogo em um único conceito. No entanto, devemos questionar os princípios que constroem aquilo que denominamos jogo, elegendo linhas de semelhanças entre diversas atividades assim nomeadas e tendo em vista nossos interesses sociológicos específicos. As teorias sociais e filosóficas acerca do jogo definiram-no, na maioria das vezes, em oposição a outras categorias: jogo $x$ trabalho, jogo $x$ seriedade, jogo $x$ falta de espontaneidade, jogo $x$ civilidade, jogo $x$ realidade, jogo $x$ vida cotidiana, e assim por diante. E em cada uma dessas variações construiu-se também, junto com a categoria jogo, uma imagem do ser humano e de suas relações sociais. Desde o século XIX, de Friedrich Schiller ([1795] 1993), passando por Huizinga ([1938] 1973) e chegando até os dias de hoje, o jogo aparece como uma dimensão essencial do humano - o que é visível em teorias no campo da estética (Schiller), da pedagogia (Friedrich Fröbel), da cultura (Huizinga), da filosofia (Eugen Fink, 1960) e da sociologia (Gebauer \& Wulf).

A partir de meados do século XX, o jogo passa a ser considerado cada vez mais um objeto de pesquisa específico e, desse modo, surgem outras maneiras de tratá-lo, não necessariamente definindo-o em oposição a outras categorias, mas permitindo abordar questões como a sua estrutura (Bateson, 2000; Caillois, [1950] 1967), sua capacidade de apresentar elementos culturais (Geertz, 1978; Caillois, [1950] 1967) e ressaltando a importância de uma análise que congregue abordagens das áreas da psicologia, sociologia, filosofia, pedagogia e psicanálise (Flitner, [1973] 1998; Scheuerl, [1955] 1975).
Em meados dos anos de 1990, ainda que de modo não totalmente disseminado, ${ }^{1}$ outros autores (Gebauer \& Wulf, 1998; Popitz, 2000; Brougère, 1995, 1999, 2004) procuraram organizar essas maneiras de pensar o jogo em um único corpo teórico, que não mais o definisse em oposição a outras categorias e que abarcasse as novas questões a respeito de sua estrutura, organização e de suas relações com a cultura. Na visão de alguns desses autores, o conceito de mimese como forma de pensar o jogo articulado a todos esses elementos desempenha papel fundamental, que permite compreendê-lo em relação complexa (e não mais em simples oposição) com a cultura, com a vida cotidiana, com a realidade e com o mundo social.

Levando em consideração essas variadas possibilidades de abordagem, é possível definir certas características do jogo infantil coletivo que, ao se associarem e interagirem entre si, estabelecem uma forma de interação específica (o próprio jogo) que é uma dimensão constituinte dos processos de socialização infantil. Tomando como base vários trabalhos citados, considero o jogo ${ }^{2}$ infantil livre, isto é, não

${ }^{1}$ Em Sutton-Smith (1978), por exemplo, o jogo infantil ainda aparece como uma categoria que se constrói em oposição à dimensão cotidiana.

${ }^{2}$ Reconheço que uma possível diferenciação entre os termos jogar e brincar - algo como ações de reprodução de normas já dadas (jogar) em oposição às ações de cunho criativo (brincar) - pode possuir, para alguns autores, função importante no plano teórico, com a finalidade de precisar conceitos ou categorias. Porém, se parto do pressuposto que os termos brincar/jogar são conceitos complexos e ambíguos, que na atividade empírica envolvem, ao mesmo tempo, reprodução e criatividade, não é imperativo diferenciá-los, pois meu objetivo é exatamente destacar essa ambiguidade, esse duplo caráter, essa relação que, como veremos com o conceito de mimese, articula elementos culturais já dados e elementos de criação. As crianças "jogam" e "brincam" ao mesmo tempo, transitando entre esses dois possíveis polos conceituais, e por essa razão não é possível afirmar a existência dessas ações de forma dicotômica, "aquelas crianças agora estão brincando, por isso são criativas. Já aquelas outras jogam, portanto apenas reproduzem padrões de comportamentos...”. Optei por 
pedagogizado ou coordenado por adultos, uma ação/ interação social específica, um processo entre seres humanos que, na infância ocidental contemporânea, realiza-se em uma temporalidade própria, como uma atividade voluntária de comunicações, descobertas, testes, imitações e construções.

Dessa perspectiva, o jogo infantil pode ser tratado como uma forma de interação específica, na medida em que proporciona comunicação com outras pessoas, objetos, animais e ambientes, além de mobilizar (e modificar) grande repertório cultural. O jogo infantil possui sua especificidade porque desempenha papel fundamental, poderíamos dizer até estruturante, nos processos de socialização infantil e na construção do self da criança - fato que não ocorre com tanta intensidade nos jogos adultos. Para compreender o jogo como tal, é necessário reconhecer a socialização infantil como uma série de processos interativos nos quais as crianças tomam parte como atores, devendo ser reconhecidas para além de sua passividade como seres humanos "incompletos", que precisam ser socializados somente por adultos. Nesse sentido, devemos considerar as crianças não como a próxima geração de adultos, mas sim como atores sociais dentro das diversas dimensões sociais nas quais transitam (inclusive a instituição escolar). "As interações das crianças não são a preparação para a vida; são já a própria vida" (Thorne, 1993, p. 3)

\section{Jogo e mimese: relações de interdependência entre dois conceitos}

Gebauer \& Wulf, inspirados em Simmel, Elias, Mead, Huisinga e Benjamin, entre outros, desenvolve-

utilizar o termo jogar em detrimento do termo brincar ou brincadeira porque ele aparece com mais frequência nos textos sociológicos que são a base deste trabalho, nos quais ele é apresentado como um conceito. Isto é, o verbo jogar aparece com mais frequência nas traduções para o português, pois tanto em alemão (spielen), como em francês (jouer) ou em inglês (to play) não existem palavras distintas para jogar e brincar. Já o substantivo jogo na língua inglesa dividese entre os termos play e game, mas que não são utilizados com a finalidade de diferenciar reprodução de criatividade. ram uma maneira inovadora de abordar o jogo infantil e suas relações com o mundo social: o conceito de mimese. Eles afirmam que, nos jogos infantis, é por meio de processos miméticos que são incorporados elementos da dimensão cotidiana; ao mesmo tempo, esses processos miméticos intermedeiam a apropriação de certos elementos dos jogos pela dimensão cotidiana. Desse modo, a mimese pode ser compreendida como um amplo arsenal de possíveis correspondências entre dois mundos, ficcionais ou não (Gebauer \& Wulf, 1998, p. 16).

O conceito de mimese, desde sua aparição em Aristóteles (Wulf, 1997), é tido como condição de sobrevivência do ser humano, como um elemento da organização social e fundamento das formações culturais. As ações miméticas são constituídas por movimentos corpóreos que incluem as mais diversas formas de interação, comunicação e linguagem (verbais ou não). O jogo infantil coletivo é uma forma de interação social permeada por ações miméticas. Pode-se afirmar que certas ações sociais são miméticas quando se constituem de movimentos que possuem correspondência com outros movimentos, isto é, no caso dos jogos, quando se percebe que os movimentos corpóreos de um determinado jogo podem ser reconhecidos em atividades da vida cotidiana; quando podem ser tratadas como apresentações corporais que possuem aspecto de representação, o que significa reconhecer que o jogo possui caráter performático e teatral. As ações miméticas são tanto ações independentes, que podem ser compreendidas em si mesmas, como também possuem correspondências com outros mundos. Isto é, os jogos são mundos próprios, mas que não estão isolados do mundo social, e sim inseridos nele, pois o jogar deve ser compreendido como uma série de ações e interações sociais específicas, nas quais as ações de jogo estão relacionadas às ações de não jogo (Bateson, 2000, p. 181).

Muitos processos sociais são miméticos (Gebauer $\&$ Wulf, 1998, p. 7). E são eles que permitem o estar no mundo corporeamente, dando forma às interações. Se o jogar infantil é uma forma de interação perpassada por processos miméticos, em mesma medida a mimese 
é uma dimensão fundamental dos processos de socialização infantil, pois intermedeia a apropriação de certos elementos da vida cotidiana e sua transformação em jogo. Essa intermediação envolve transformação, o que significa que a mimese opera não apenas no registro da reprodução dos elementos da vida cotidiana, mas na sua transformação, recriação, recontextualização. É isso que faz do jogo - e dos processos de socialização - atividades criativas.

Portanto, entre a ordem interna dos jogos e a ordem social há uma relação mimética. Os jogos tomam de empréstimo ações e significados das práticas do dia a dia e ressemantizam esses significados e ações. São um segundo mundo, que se baseia em princípios de ordem do mundo da experiência (um primeiro mundo). Desse modo, diversas formas pelas quais a cultura se organiza revelam-se neles. Essas formas de organização não são produzidas no interior dos próprios jogos, mas o ato de jogar toma parte nessa ordem, empresta expressões de sentido. "Nas ações miméticas, o indivíduo cria seu mundo próprio, mas relacionado com um outro mundo que - na realidade ou na imaginação - já existe" (idem, ibidem). Assim, os jogos são mundos próprios, mas os seus princípios de organização (estruturas e processos) estão impregnados do social; nesse sentido, gozam de relativa autonomia, mas, ao mesmo tempo, por meio de processos miméticos, estão relacionados a outros mundos, para além do mundo do jogo.

A articulação de práticas sociais e jogar infantil, própria dos processos miméticos, engloba várias categorias do agir social. Entre essas categorias podemos citar os diversos modos de organização da sociedade e as formas de relação de indivíduo e sociedade; estas envolvem a estratificação social, as relações raciais e de gênero, ou seja, as mais diversas variáveis de morfologia social ou de estilos de vida. Essas categorias são fundamentais para a construção dos jogos; sem elas os jogos não seriam possíveis. São fundamentais também para construir a ideia de parceiros de jogo ou adversários e as relações que se estabelecem entre eles. Isso significa que os jogos não são espelhos de nós mesmos ou de um grupo de crianças, mas constituem- se por meio de todos esses elementos. É evidente que esses elementos não são universais, mas podem ser considerados culturais, de uma cultura ocidental - pois em outras culturas talvez outros aspectos do agir social obtenham destaque.

Embora todos os elementos constitutivos da dimensão cotidiana possam ser expressos no jogo, nem todos eles são selecionados pelos jogadores, pois a mimese faz do jogo um mecanismo seletivo e, desse modo, ao jogar as crianças ao mesmo tempo manipulam certos elementos sociais e culturais e estabelecem uma relação individual - portanto, seletiva - com esses elementos (Brougère, 1995).

A relevância dos processos miméticos para o caráter criativo do jogar demonstra que essa criatividade deve ser pensada sempre nas relações com o outro, e não como um acontecimento solitário. A criatividade da mimese encontra-se na sua capacidade de estabelecer novas relações com outros mundos, e, dessa perspectiva, mimese não se confunde com imitação. Os acontecimentos nunca são idênticos, mas semelhantes, impenetravelmente semelhantes entre si, e é essa semelhança - que não é idêntica porque está continuamente estabelecendo outras e novas relações, porque está a cada vez em outro contexto, recriando-o - que permite o surgimento do novo (Benjamin, 1985).

O elemento de criatividade nos processos miméticos que permeiam o jogo infantil está intrinsecamente ligado às capacidades da imaginação e fantasia no período da infância. A fantasia é um produto específico da capacidade de imaginação, é ela que conduz à criatividade e possibilita tornar presente o ausente. Dessa forma, no jogo infantil, mimeticamente, os caminhos da fantasia apontam e revelam como as crianças organizam, criam e recriam o seu estar no mundo, sendo possível, por meio da fantasia, que as crianças experimentem o quão alta uma torre pode ser sem precisar subir nela (Popitz, 2000, p. 84-85).

Pensar o jogo em relação com o mundo social permite, por um lado, explicitar as formas pelas quais essa relação se constitui e os elementos que são tomados de empréstimo da vida cotidiana, mas permite também pensá-lo como uma ação independente, 
que pode ser analisada em si mesma. É por isso que, para Huizinga, o jogo é visto como uma categoria absolutamente primária da vida, que é reconhecida pelo senso comum como uma forma específica de atividade, uma qualidade de ação bem determinada e distinta da vida comum. Cria-se outro mundo, que se distingue da vida comum pelos seus limites de duração, de tempo e de espaço, em que o jogar envolve certo isolamento, certa limitação. Em virtude desse distanciamento das práticas sociais, o jogo pode ser compreendido por si mesmo. Nele, as práticas sociais são modeladas e remodeladas segundo regras e modos próprios - perpassadas por ações brincantes, jogantes e, portanto, miméticas - que permitem precisamente a sua diferenciação perante o mundo.

\section{Mimese como mediação de jogo infantil, processos de socialização e construção do self}

Nos processos de socialização infantil, o self desenvolve-se por meio das interações que as crianças estabelecem, quer com adultos quer com crianças. $\mathrm{O}$ jogo infantil coletivo é uma dessas interações e desempenha papel fundamental na construção do self. Dentre os sociólogos, Mead foi o autor que mais se empenhou em perceber como as relações entre o eu e o outro no jogar desempenham importante papel nos processos de socialização, demonstrando como o "jogar é sempre um jogar com" (Plessner, [1941] 2003, p. 286; Waizbort, 2000, p. 107) e inspirando grande parte das teorias posteriores sobre o assunto. A concepção de jogo, para Mead, envolve atitudes distanciadas do próprio eu, dos desejos imediatos e do próprio acontecimento do jogar. São atitudes que se orientam com base no outro, de um outro generalizado.

Segundo Mead, há dois estágios gerais do desenvolvimento do self. O jogo infantil está presente em ambos e pode ser visto como uma ilustração da maneira pela qual ocorrem os amplos processos que envolvem o desenvolvimento do self na infância. No primeiro desses estágios, o self individual é constituído simplesmente pela organização das atitudes particulares de outros indivíduos para com a criança, isto é, a criança parece ainda não perceber plenamente que interage com pessoas em sociedade, e não apenas com pessoas isoladas. A forma de jogar mais recorrente nesse período específico da infância é denominada, por Mead, play. Ao jogar o play, as crianças reagem aos estímulos imediatos que chegam a elas, mas esses estímulos não estão organizados de forma que, com base neles, elas possam organizar seu self. Um exemplo desse tipo de jogo são aqueles em que as crianças parecem jogar consigo mesmas e desempenham diversos papéis ao mesmo tempo: são simultaneamente mamãe e filhinha, motorista de ônibus e passageira etc., exatamente por ainda não dimensionarem que esses papéis fazem parte de uma rede de interdependências maior.

No segundo estágio do desenvolvimento do self individual, ele é constituído não apenas por uma organização das atitudes particulares individuais dos outros, mas também por uma organização das atitudes sociais do outro generalizado ou o grupo social como um todo ao qual a criança pertence. Essas atividades sociais ou grupais são trazidas para o campo individual da experiência direta e são incluídas na estrutura ou constituição do self da mesma forma que as atitudes do outro particular individual o são. A forma de jogo que corresponde a esse estágio do desenvolvimento do self é denominada, por Mead, game, uma forma potencialmente coletiva de jogar. O game é uma ilustração da situação por meio da qual o self emerge e representa uma passagem na vida da criança na qual ela começa a assumir o papel de outros no jogo de forma organizada, que é essencial para o desenvolvimento do seu self e da sua consciência do self.

Ao jogar o game, as crianças assumem um papel dentro desse jogo, mas, além disso, elas precisam estar prontas para assumir o papel de qualquer outra criança envolvida no mesmo jogo. ${ }^{3}$ Isto é, para desempenhar o seu próprio jogo elas precisam saber o que cada um dos

${ }^{3} \mathrm{O}$ assumir o papel do outro possui um caráter específico: papel não tem o mesmo significado que para diversas teorias funcionalistas; papel é algo individual e circunstancial, ou seja, processual, e não algo já dado de antemão. 
outros jogadores pode fazer, a ordem possível dessas realizações e as maneiras como podem ocorrer. Elas precisam conhecer todos esses papéis e as variáveis e ser capazes de assumi-los mentalmente durante os processos de jogo. Eles não estão todos conscientemente presentes ao mesmo tempo, mas à medida que o jogo se desenrola os papéis vão aparecendo como referências para o seu próprio jogar, de sorte que há uma série de reações dos jogadores de tal maneira organizadas que a atitude de um desencadeia a atitude apropriada do outro (sem o que o jogo acabe). Nesse contexto, os jogadores estão tão empenhados em uma ação comum - o jogo - que esse empenho coletivo promove a continuidade do próprio jogo. E, além disso, essa concentração tão intensa no outro permite que as crianças saiam de si (Popitz, 2000, p. 102) e desenvolvam seu self.

Os processos miméticos no jogar são o modo pelo qual esse conhecer o papel dos outros jogadores ocorre. A mimese enfatiza a importância do outro nos processos de socialização, nos processos de construção do self e no jogar, pois, sem relações e interações com os outros não há mimese, e sem mimese não é possível interagir. Para assumir mentalmente o papel dos outros jogadores, cada criança precisa sair de si e assemelharse aos seus companheiros para, só então, conhecer esses papéis e ser capaz de assumi-los. No jogo, ao exercitar esse assemelhar-se aos elementos, às pessoas e aos papéis do mundo social, as crianças desenvolvem a percepção do outro generalizado, o qual desempenha um papel fundamental para o desenvolvimento do self na infância.

O desenvolvimento da percepção do outro generalizado no jogo funciona como organização das ações e comunicações de todos aqueles envolvidos nos mesmos processos. Essa organização está instalada na forma das regras do jogo, que são a série de reações que uma atitude particular pode despertar (independentemente de se concretizar ou não). Essas reações precisam estar, em muitos graus, presentes no próprio fazer/inventar da criança que joga. E, para que isso ocorra, esses diferentes papéis precisam estabelecer e manter relações de reciprocidade uns com os outros; do contrário, não seria possível internalizá-los - o que não impede que haja criatividade, mas define seus limites. Assim, não é apenas o jogador que é ativo, mas também com quem (ou com o que) ele joga. "Jogar não significa apenas jogar com alguma coisa (ou jogar alguma coisa), mas também que algo joga com o jogador" (Plessner, [1941] 2003, p. 286), pois quando jogamos estamos confrontados com um outro, e esse outro nos responde (Simmel, [1908] 1992).

O jogo é a forma mais simples de ser outro em si mesmo (McCarthy \& Das, 1992), e isso permite que "o individual experiencie a si mesmo" (Mead, [1934] 1952 , p. 80) - indiretamente e não diretamente - por meio do olhar específico dos outros jogadores. No entanto, não deve ser compreendido como um reconhecer a si mesmo passivo por meio do olhar do outro, mas traz consigo experiências diferenciadas e contraditórias. $\mathrm{O}$ antecipar a conduta do outro não significa agir em conformidade com ela, mas também contestá-la, pois não se trata simplesmente de uma capacidade cognitiva, consiste em uma capacidade de interação social. "Para a identidade é fundamental que a pessoa reaja sobre si mesma" (idem, p. 184). A construção de uma identidade depende de processos de autopercepção, autovaloração e autorreflexão (Scherr, 2002, p. 54). O jogo infantil permite, ao mesmo tempo, desenvolver e diferenciar o self individual dos outros selves, e isso representa uma etapa fundamental dos processos de socialização infantil.

Quando as crianças exercitam o assumir a perspectiva do outro, elas veem não apenas o mundo da perspectiva do outro, mas também a si mesmas como parte desse mundo: isso é o desenvolvimento de uma identidade. "Nós precisamos ser outros se queremos ser nós mesmos" (Popitz, 2000, p. 18). A dimensão de fantasia no jogar nos transporta para além de nós mesmos, a uma outra realidade na qual podemos nos conhecer e nos reconhecer como outros. A categoria ser outro faz o ser humano criativo, porque faz enxergar o mundo sob a luz de outras possibilidades - o descentramento de si mesmo que, de maneira ambivalente, permite o autoconhecimento/ desenvolvimento (idem, p. 98-100). 
Experienciar a si mesmo por meio do desenvolvimento da percepção do outro generalizado consiste em desenvolver uma reflexividade sobre si mesmo e sobre o seu self individual. Quando a criança assume o papel do outro, ela é capaz de ver a si mesma a partir desse outro lugar, ver a si mesma como um objeto, com um distanciamento que a faz refletir sobre si mesma (McCarthy \& Das, 1992). O desenvolvimento do self nos processos miméticos do jogar permite às crianças organizar e interpretar suas próprias experiências na vida social. Dessa forma, o jogar funciona como uma objetivação do self, isto é, o self é tratado como objeto. E, para que o self emerja, não apenas a criança deve enxergar a si mesma e ao seu self em construção como objeto como também as pessoas e os objetos do mundo social devem ser percebidos como externos à criança.

Além disso, no jogo, as crianças desenvolvem não apenas a capacidade de ver a si mesmas como objeto e perceber que os outros e as outras entidades possuem uma existência independente, mas também desenvolvem a habilidade de unir diversas perspectivas na sua própria experiência, que tomam corpo na forma do outro generalizado. Desse modo, no jogo, elas experimentam ser o outro e elas mesmas simultaneamente, e compreendem essas duas posições como em relação uma com a outra (McCarthy \& Das, 1992).

Aquilo que se manifesta no jogo exprime-se continuamente na vida social das crianças (e na sua socialização). Esses amplos processos vão muito além das suas experiências imediatas; nesse sentido, o jogo é também um modelo da situação por meio da qual transcorrem os processos de socialização infantil. Tais processos possuem o caráter mimético; as crianças incorporam diversos elementos constitutivos da sociedade (regras, valores, formas de agir e ser, maneiras de pensar etc.) e se tornam parte dela. A maneira como esses elementos aparecem no jogo, muitas vezes, faz mais sentido para as crianças do que a maneira como eles se apresentam em outros âmbitos sociais, porque o jogo exprime uma situação social na qual elas podem entrar completamente, de maneira ativa, diferentemente de diversas outras atividades que são controladas e/ou dirigidas por adultos e mais direcionadas para a categoria e o mundo adulto, em que as crianças participam apenas parcialmente. ${ }^{4}$

O jogo infantil coletivo traz consigo a experiência de confiar no mundo e a da previsibilidade (sempre relativa) dos acontecimentos sociais, que se desenvolve juntamente com a experiência do interagir ("eu posso realizar algo nesse mesmo mundo") e, portanto, de antecipar a conduta dos outros. No jogo, os processos e as estruturas do mundo social tornam-se conhecidos, podem ser antecipados (Popitz, 2000, p. 63). O antecipar a conduta do outro e a previsibilidade de certas ações sociais, tanto nos processos de socialização como no jogo, significam um conhecer mais e melhor a própria cultura - são o que Popitz denomina repetições modificadas. Essa expressão é que permite compreender a ambiguidade presente no conceito de mimese e o complexo significado do "assumir o papel do outro" em Mead. Nesse sentido, os processos de socialização, assim como o jogo, ocorrem de forma relativamente previsível, por serem permeados por processos miméticos que envolvem recriação daquilo que é incorporado mimeticamente.

Os gestos, nossos e dos outros, são carregados de significados, e as crianças aprendem isso ao jogar assumindo o papel do outro (McCarthy \& Das, 1992). No ato de jogar coletivamente revela-se muito das relações interindivíduos: os gestos, os concorrentes, os espectadores, os observadores, as tensões, as relações de poder, os parceiros de jogo. Sentimentos, táticas,

\footnotetext{
${ }^{4}$ No jogar, em seu fazer como se, as crianças atingem a zona de desenvolvimento proximal de Vygostsky, pois expressam conhecimentos sobre situações que estão além daquilo que já viveram como crianças (Goldman, 1998, p. 5.). Em virtude do fazer como $s e$, as crianças vivenciam certos tipos de relações que só poderiam vivenciar muito tempo depois, na vida adulta, no sentido mais amplo do que significaria antecipar a conduta do outro, que seria “antecipar” experiências como a de ser pai ou mãe ou de tomar decisões como a escolha do destino de uma viagem ou o exercer uma profissão. E, mesmo quando as crianças assumem, jogando, por exemplo, o papel de mãe, essa experiência abre caminhos para outras descobertas/experiências (Popitz, 2000, p. 92).
} 
estratégias, regras, expectativas são sinalizados e simbolizados de forma objetiva no jogo. Possuem sentido prático e constrói-se um saber prático sobre esses elementos; eles não se reduzem a conceitos abstratos ou generalizações. Assim, as ações de jogo podem ser vistas analiticamente como mediações de indivíduo e sociedade. Pular, correr, escalar pode ser divertido, mas, sem uma relação de correspondência com um outro (ou com uma outra coisa que não a si mesmo), eles não são jogos. Todas as formas de jogo são estruturas dialógicas, implicam um diálogo com algo, um fazer com.

Os processos miméticos fazem com que a identidade individual (self), o mundo social e o mundo do jogo estabeleçam uma relação de interdependência e de referencialidade mútua na infância. Ao jogar, as crianças apropriam-se de maneira subjetiva do "espírito" do meio social ao qual pertencem, ao mesmo tempo em que constroem uma identidade em relação e em tensão com esse mundo.

\section{Análise de duas imagens de Infância em Berlim por volta de 1900, de Walter Benjamin}

Diversas imagens da infância contidas no escrito de Walter Benjamin Infância em Berlim por volta de 1900 ([1932-1933] 1987) podem ser interpretadas como uma espécie de síntese das maneiras como ocorrem os processos miméticos no jogar infantil e seu papel na constituição do self nos processos de socialização. Os textos permitem vislumbrar em profundidade os processos miméticos, como mediação de jogo infantil e processos de socialização; com isso em vista, analiso duas dessas imagens, "A Mummerehlen" e "O Corcundinha".

No centro de Infância em Berlim por volta de 1900 encontra-se a faculdade mimética, que proporciona um caráter muito peculiar ao texto, modelando-o desde a raiz. As imagens presentes nos textos não evocam apenas um passado individual, como na concepção usual de autobiografia; são imagens da cultura cotidiana que registram, ao mesmo tempo, traços de uma biografia individual e vestígios de uma história coletiva, imbricadas uma na outra. O sujeito da biografia joga com o oculto, explorando os processos de se encontrar e se perder, compondo e organizando, dessa forma, sua memória. Benjamin concebe sua própria infância como tornar-se semelhante ao mundo circundante e sua escrita, como leitura e decifração, na memória, das correspondências com esse mundo (Gebauer \& Wulf, 1992). Nessas imagens, seu eu é constantemente esvaziado, pois se assemelha o tempo todo àquilo que está fora dele, e é precisamente esse esvaziamento do eu que torna possível a construção do self. Muitas dessas imagens podem ser vistas como imagens do jogar, ${ }^{5}$ visto que retratam momentos da vida cotidiana de Benjamin quando criança, nos quais diversas atividades - como alimentar-se, passear pela cidade, observar objetos e quadros, ler livros, tirar fotografias, ouvir conversas de adultos - eram realizadas na forma de brincadeira.

\section{"A Mummerehlen"}

Benjamin, ao rememorar sua infância na forma de imagens, fornece muitos exemplos de como ocorre a busca por sentido, por meio do jogar, para os diversos elementos da dimensão cotidiana, isto é, como ocorrem os processos de socialização infantil. E os processos miméticos medeiam essa busca. A Muhme Rehlen era, originalmente, tema de alguns versinhos entoados para Benjamin quando criança por pessoas adultas. Benjamim desconhecia o significado dessas palavras e, jogando com palavras e objetos, procurava desvendar seus possíveis significados. Nessa busca de sentido, mimeticamente e na forma de jogo, Benjamin acabava por dotar de novos significados aquilo que lhe era desconhecido, como a Muhme Rehlen.

\section{É numa velha rima infantil que aparece a Muhme Rehlen. \\ Como na época Muhme nada significava para mim, essa}

${ }^{5}$ Um olhar do adulto sobre o seu jogar quando criança, como uma forma de rememorar não apenas o seu passado mas também as maneiras pelas quais as crianças sentem, veem e se relacionam com o mundo social por meio do jogar. 
criatura se tornou em minha fantasia uma assombração: a Mummerehlen. Os mal-entendidos modificavam o mundo para mim. De modo bom, porém. Mostravam-me o caminho que conduzia ao seu âmago. Qualquer pretexto lhes convinha.

Assim, quis o acaso que, certo dia, se falasse em minha presença a respeito de gravuras de cobre. No dia seguinte, colocando-me sob uma cadeira, estiquei a cabeça - $\mathrm{a}$ isso chamei de "gravura de cobre". Mesmo tendo desse modo deturpado a mim e às palavras, não fiz senão o que devia para tomar pés na vida. A tempo aprendi a me mascarar nas palavras, que, de fato, eram como nuvens. $\mathrm{O}$ dom de reconhecer semelhanças não é mais que um fraco resquício da velha coação de ser e se comportar semelhantemente. Exercia-se em mim por meio de palavras. Não aquelas que me faziam semelhante a modelos de civilidade, mas sim às casas, aos móveis, às roupas. (Benjamin, [1932-1933] 1987, p. 99)

Em alemão, gravura de cobre e ação de esticar a cabeça escrevem-se respectivamente Kupferstich e Kopfverstich, e, pela semelhança de som dessas duas palavras, Benjamin fez com que seu significado também fosse semelhante, já que não conhecia o significado de gravura de cobre (Kupferstich). Ele denominava esses processos miméticos mal-entendidos, porque não eram entendidos da forma usual. Mal-entendidos que eram capazes de modificar significados de diversos elementos do mundo social, pois faziam com que fossem entendidos de outras formas, criando assim um outro mundo, próprio da criança que mobiliza essas semelhanças: o mundo do jogo infantil.

Na infância, em comparação com a vida adulta, a faculdade mimética é executada no jogar exaustivamente. As crianças possuem uma capacidade muito maior do que os adultos de conectar, por semelhanças, imagens a palavras. Mas quando desenvolvem plenamente a linguagem e a escrita e tornam-se adultas, deixam de lado parte do uso dessa capacidade; a linguagem e a escrita passam a intermediar essa relação entre imagens e palavras. Basta dizer uma palavra a uma criança para ela, por semelhanças, passar a representá-la na forma de uma imagem - seja com o corpo, no jogar, desenhando ou apenas na imaginação (Opitz, 2000, p. 28-29, 43-44).

Quem lê com atenção o texto "A Mummerehlen", percebe que Benjamin escreve essa palavra às vezes com $m$ (Munmerehlen), às vezes com $h$ (Munmerehlen). Rehlen provavelmente é um nome próprio. Muhme ( com $h$ ) é como aparece na rima original; em alemão significa tia, uma denominação que, já à época de Benjamin, encontrava-se em desuso. Poderíamos então ler Tia Rehlen. Em decorrência do seu desuso, a criança Benjamin não sabia o que significava Muhme (com $h$ ), e, por semelhança, buscou uma palavra aproximada que lhe fizesse sentido: Mumme (com $m$ ), palavra utilizada principalmente por crianças pequenas para denominar máscara em alemão. Então, para Benjamin, Mummerehlen significava Rehlen Mascarada ou Rehlen Fantasiada. Algo que permanecia incógnito, a cargo de sua imaginação. Ele diz: "O versinho está deturpado; entretanto, cabe nele todo o mundo deturpado da infância. Já não se tinha lembrança da Muhme Rehlen, que outrora nele se achava, quando me foi explicado pela primeira vez" (Benjamin, [1932-1933] 1987, p. 100).

Quem entoava esses versos para Benjamin não se preocupou em explicar (ou não sabia) o que era a Muhme, pois não havia nexo necessário entre o tempo presente de Benjamin e aquilo que era lido, cantado, recitado, como um resquício de algo que fizera sentido em tempos passados. Só restou o verso. O exemplo da Mummerehlen é duplamente bem-sucedido, porque, por um lado, ela aparece como algo incógnito, por ser mascarada (o significado da palavra Mumme); ao mesmo tempo, por seu significado original (Muhme = tia) ter sido mascarado, escondido para ele. Coube à criança, assemelhando-se ao mundo circundante, tentar descobrir o significado, isto é, criar um significado. Para o Benjamin adulto, a Mummerehlen tornou-se símbolo de todo esse mundo deturpado da infância, como se fosse a representante da criança no seu processo de se encontrar e se perder.

Pensar na busca pela imagem da Mummerehlen é pensar também, nos termos de Benjamin, na busca da imagem de si na criança, do seu self. Ao jogar com 
os objetos ao seu redor, a criança Benjamin nunca se fazia semelhante à sua própria imagem, pois o que lhe permitia construir o seu self era o ato de esvaziar o próprio $e u$, como veremos mais adiante em "O Corcundinha”. Assim como no jogo infantil, também em outras atividades o eu é esvaziado para dar lugar ao self. O sonho é uma delas. A passagem seguinte, contida no texto "A imagem de Proust" (Benjamin, [1936] 1985), evidencia e trabalha as semelhanças entre o jogar e o sonhar:

Portas imperceptíveis a ele conduzem (ao sonho). É nele que se enraíza o esforço frenético de Proust, seu culto apaixonado da semelhança. Os verdadeiros signos em que se descobre o domínio da semelhança não estão onde ele os descobre, de modo sempre desconcertante e inesperado, nas obras, nas fisionomias ou nas maneiras de falar. A semelhança entre dois seres, a que estamos habituados e com que nos confrontamos em estado de vigília, é apenas um reflexo impreciso da semelhança mais profunda que reina no mundo dos sonhos, em que os acontecimentos não são nunca idênticos, mas semelhantes, impenetravelmente semelhantes entre si. As crianças conhecem um indício desse mundo, a meia, que tem a estrutura do mundo dos sonhos, quando está enrolada, na gaveta de roupas, e é ao mesmo tempo "bolsa" e "conteúdo". E, assim como as crianças não se cansam de transformar, com um só gesto, a bolsa e o que está dentro dela, numa terceira coisa - a meia -, assim também Proust não se cansava de esvaziar com um só gesto o manequim, o Eu, para evocar sempre de novo o terceiro elemento, a imagem, [...] a imagem de si, o seu self. (Benjamin, [1936] 1985, p. 39-40)

A mesma metáfora do manequim aparece em "A Mummerehlen" na figura da mãe, que acompanha Benjamin ao fotógrafo. Ao ser fotografada, a mãe se porta como um manequim e deseja que seu filho também se comporte como tal. Ele, porém, está desfigurado pela semelhança com tudo o que está à sua volta: pelos objetos, pelas fotos de animais, pelas plantas. E é exatamente pelo fato de seu eu estar desfigurado pelos objetos à sua volta que ele é capaz de vislumbrar uma imagem de si. Esse estar desfigurado pode ser entendido como um esvaziar o manequim por meio de processos miméticos; como o exercer um autodistanciamento, que é a faculdade mimética, assemelhando-se ao mundo circundante.

Tais semelhanças não precisam estar dadas de antemão para a criança, mas o contrário: as semelhanças são encontradas, imaginadas, fantasiadas no momento do jogar; é por isso que tudo para a criança pode ser um brinquedo em potencial; um pedaço de pau pode se transformar em uma pessoa, uma pedra, em uma panelinha e assim por diante. Ao inventar histórias, as crianças são cenógrafos que não se deixam censurar por uma coerência de sentido já preestabelecida e naturalizada pelo mundo adulto. E é por isso que a infância pode ser pensada como tornar-se semelhante ao mundo circundante, porque isso é feito espontânea e criativamente na forma do jogo.

$\mathrm{O}$ adulto Benjamin descreve autorreflexivamente o procedimento: "Como um molusco em sua concha, eu vivia no século XIX, que está agora oco diante de mim, como uma concha vazia. Levo-a ao ouvido" ([1932-1933] 1987, p. 99-100). Benjamin esvaziou essa concha como Proust esvaziou o manequim, o eu, e, estando ela vazia, leva-a ao ouvido. O zunido que se ouve ao fundo é a imagem que é evocada pelo exercício da faculdade mimética, o que lhe permite escrever sobre sua própria infância na forma de imagens. Não se assemelhando a pessoas, a modelos, ou melhor, modelos de civilidade, como diz Benjamin, a criança pode se tornar sujeito em seu próprio mundo, e não uma cópia de como os adultos, ou simplesmente os outros, são e se comportam no mundo dos adultos.

Já que para Benjamin a Mummerehlen passou a significar Rehlen Mascarada ou Rehlen Fantasiada, e Rehlen era um nome próprio designando algo indeterminado (pessoa, objeto, animal, coisa, ser sobrenatural...?), coube à criança tentar desmascará-la.

Seguir o paradeiro da Mummerehlen foi, contudo, ainda mais difícil. Ocasionalmente eu a supunha no macaco que nadava no prato fundo em meio aos vapores da sopa de cevadinha ou de tapioca. Tomava a sopa a fim de fazer mais clara sua imagem. (Benjamin, [1932-1933] 1987, p. 100) 
O prato cheio de sopa oculta o que há no fundo. A ideia de esvaziar o prato de sopa para fazer mais clara a imagem da Mummerehlen, que talvez nadasse em seu fundo, pode ser comparada à ideia de esvaziar o manequim, a concha, para a imagem se fazer clara. "Talvez morasse no lago Mummel (lago legendário na Floresta Negra), cujas águas dormentes talvez aderissem a ela como uma pelerine cinzenta. O que me contaram sobre ela - ou o que só quiseram me contar - não sei” (idem, p. 100). Agora Benjamin tenta descobrir uma vez mais o que é a Mummerehlen pela semelhança, tanto na escrita como no som, e em seu significado, pois o lago Mummel é um lago que fica na Floresta Negra, escura, que não deixa ver com clareza. E, caso ela morasse mesmo no lago, suas "águas dormentes talvez aderissem a ela como uma pelerine cinzenta" (idem, ibidem), cobrindo, mascarando, escondendo.

"Ela era o Mudo, o Movediço, o Tormentoso, que, como a nevasca nas bolas de cristal, nubla o núcleo das coisas" (idem, ibidem). Além de ser mascarada, aparece como muda, que não se comunica pela fala. Movediça, a cada momento aparece em um lugar diferente e nunca permanece, é algo obscuro. Como uma tormenta, uma tempestade violenta, desordem, que se agita o tempo todo, movimenta-se, movediça. Benjamin a compara com a nevasca nas bolas de cristal, nevasca essa que vem de todos os lados e por isso oculta e nubla, torna invisível a casinha que está no centro da bola. Esse é o processo em que se dá o surgimento da imagem, como um relâmpago. Aqui a Mummerehlen aparece ao mesmo tempo como a máscara e como a imagem que se esconde por detrás dela. A máscara é parte constituinte da própria Mummerehlen. A Mummerehlen é, ao mesmo tempo, a nevasca que nubla e o núcleo das coisas que Benjamin tanto quer descobrir.

\footnotetext{
Às vezes, sentia-me carregado nesse meio. Isso me ocorria ao pintar com nanquim. Quando misturava as cores, elas me tingiam. Mesmo antes de colocá-las no desenho, me envolviam. Quando, ainda úmidas, se imiscuíam umas às outras, tomava-as no pincel com tanto cuidado como se fossem nuvens se diluindo. (idem, ibidem)
}

Ele mesmo, sua identidade, sentia-se mascarado, nublado. As cores da tinta eram como nuvens que envolviam, tingiam ele próprio. Mas, ao mesmo tempo em que essas nuvens escondiam e nublavam o núcleo das coisas, isto é, o núcleo dele mesmo, elas o carregavam nesse meio, no meio delas mesmas. Pois há uma grande diferença entre apenas contemplar a nuvem (quando não se vê o que está por detrás dela, aquilo que ela própria está nublando) e ser carregado por ela, no meio dela, ser envolvido e, dessa forma, ficar mais próximo do núcleo das coisas (e de seu self), ser capaz de percebê-lo.

A fantasia emerge quando as cores ainda estão úmidas, ainda não se fixaram no tempo e no espaço, e se imiscuem umas às outras. A fantasia aparece quando a superfície colorida é apenas sugerida; ela não aparece simplesmente da cor inanimada, sem vida, fixada. É desse anseio por exercitar a faculdade mimética, que aqui encontra seus limites, que a fantasia emerge.

Na maioria das vezes, esses processos acontecem na forma de jogo. A nuvem que nubla impele a criança a mergulhar dentro dela, a tentar descobrir aquilo que está escondido, fazendo com que a criança crie para si uma imagem das coisas que estão incógnitas, uma história que para ela faça sentido, e é isso que faz com que as crianças adentrem no mundo das coisas, mergulhando em cada objeto, tinta e cor. Criando essa conexão com os objetos, os animais, as plantas, ligando-se e assemelhando-se a eles, as crianças criam e inserem-se no mundo: socializam-se. Mergulham na nuvem, são levadas por ela e chegam mais perto do núcleo das coisas. Tornam-se capazes de formar uma imagem de si, de serem elas mesmas, sujeitos; não são reduzidas a um manequim.

\footnotetext{
Mas, de tudo o que reproduzia, minha preferência era a porcelana chinesa. Uma crosta multicor cobria cada vaso, vasilhame, prato, tigela, que certamente não passavam de artigos de exportação baratos. Porém, cativavam-me tanto como se, já naquela época, eu conhecesse a história que, mais uma vez, depois de muitos anos, me remeteu à obra da Mummerehlen. A história provém da China e fala de um pintor idoso que permitiu aos amigos admirarem sua tela
} 
mais recente. Nela estava representado um parque, um caminho estreito que seguia ao longo da água e através de umas folhagens e que terminava em frente de uma pequena porta que, no fundo dava acesso a uma casinha. Eis que quando os amigos procuraram o pintor, este já se fora, tendo penetrado no próprio quadro. Ali percorreu o caminho estreito até a porta, deteve-se calmamente diante dela, virou-se, sorriu e desapareceu pela fresta. Assim também, com minhas tigelas e meus pincéis, subitamente me transportava para dentro do quadro. Assemelhava-me à porcelana na qual fazia minha entrada com uma nuvem de cores. (Benjamin, [1932-1933] 1987, p. 100-101)

O pintor chinês não contemplou apenas seu quadro, mas adentrou nele, assim como a ideia do entrar na nuvem, e não apenas contemplá-la. Benjamin, assemelhando-se aos objetos, mergulhando neles, abriu uma entrada para seu próprio quadro, isto é, uma entrada que permite construir uma imagem de si, como no primeiro parágrafo de "A Mummerehlen": "Os mal-entendidos modificavam o mundo para mim. De modo bom, porém. Mostravam-me o caminho que conduzia ao seu âmago". A ideia que perpassa todo o texto é a de que foi aberta uma entrada que conduz a um caminho e que esse caminho conduz a uma imagem, e não de que é aberta uma entrada que conduz diretamente à imagem. É dada a possibilidade de seguir esse caminho que a entrada indica, mas o seguir esse caminho rumo à imagem é somente uma possibilidade. E é uma possibilidade no instante de um relampejar. A construção do self implica percorrer esse caminho, o caminho do jogar e dos processos miméticos.

Na leitura de Gebauer \& Wulf(1992), a Mummerehlen aparece como caminho que liga a imagem à realidade, na união mimética do pintor e seu quadro, sendo uma mediação entre o espaço real e o do quadro. É uma imagem para a relação mimética dos seres humanos com o mundo; demonstra como ocorrem os processos de socialização por meio do jogar. Poderíamos então dizer que a Mummerehlen (que a meu ver simboliza o próprio jogar) aparece como caminho que liga a construção do self (a imagem de si) aos processos de socialização (ao mundo social, à realidade).
O espaço do real e o do quadro tornam-se um único espaço (indiferenciado, espaço de imaginação, criatividade, ação e realidade) na infância; a criança assemelha-se às coisas de tal modo que estas se tornam parte da criança.

Também as coisas podem se tornar semelhantes às crianças, sempre como jogo. Na imagem "Caçando borboletas", Benjamin assinala essa possibilidade:

\section{[...] quanto mais me achegava com todas as fibras ao inseto, quanto mais assumia intimamente a essência da borboleta, tanto mais ela adotava em toda ação o matiz da decisão humana, e, por fim, era como se sua captura fosse o único preço pelo qual minha condição de homem pudesse ser reavida. (Benjamin, [1932-1933] 1987, p. 81)}

Nota-se aqui uma ampliação das possibilidades tanto da criança como do animal. Porém, o aprisionamento da borboleta permite assegurar o limite entre a criança e o animal. $\mathrm{O}$ domínio do objeto permite a construção do mundo da criança.

Para Benjamin, a percepção do semelhante ocorre em um relampejar, estando vinculada a uma dimensão temporal. "Ela perpassa, veloz, e, embora talvez possa ser recuperada, não pode ser fixada, ao contrário de outras percepções" (Benjamin, [1933] 1985, p. 110). Como no caso das tintas tomadas no pincel, que, em instantes, eram como nuvens que já se diluíram; e como o próprio jogar, que se realiza em uma temporalidade própria e depois que acaba não deixa nada "concreto" atrás de si.

O programa infantil Castelo Ra-Tim-Bum, de Cao Hamburger, fornece um exemplo interessante desse aspecto da temporalidade própria do jogar, mais uma vez permitindo explorar as semelhanças entre "mundo do jogo" e "mundo dos sonhos". Em certo episódio, tio Vítor, uma espécie de mágico, inventa uma máquina fotográfica que é capaz de fotografar os sonhos (desejos) das pessoas. Após tirar uma fotografia instantânea na qual os sonhos de todos os personagens aparecem na imagem, seu sobrinho Nino, muito contente, comenta que esse retrato deve ser colocado em uma bela moldura. Mas tio Vítor o desaponta dizendo 
que isso não será possível. Nino pergunta: "Por quê?”. E tio Vítor responde: "Porque é muito difícil guardar a imagem de um sonho".

"O Corcundinha"
Quando à adega vou descer
Para um pouco de vinho apanhar
Eis que encontro um corcundinha
Que a jarra me quer tomar.
Quando a sopinha quero tomar
É à cozinha que vou
Lá encontro um corcundinha
Que minha tigela quebrou.
Quando ao meu quartinho vou
Meu mingauzinho provar
Lá descubro o Corcundinha
Que metade quer tomar.
Por favor, eu te peço, criancinha,
Que reze também pelo Corcundinha.
(Benjamin, [1932-1933] 1987, p. 142)

O Corcundinha é um personagem recorrente em fábulas, contos, poemas e canções infantis da infância benjaminiana. Mas, assim como a Mummerehlen, seus significados extrapolam as margens das páginas dos livros infantis. Para o adulto que rememora sua infância, o Corcundinha é apresentado como o autor das imagens da lembrança (Stüssi, 1977), podendo ser considerado também "o representante privilegiado da inabilidade, do fracasso e do esquecimento, ou, ainda, de tudo o que escapa à soberania do sujeito consciente" (Gagnebin, 1994, p. 94). Para o Benjamin criança, o Corcundinha desempenha um papel fundamental em seus processos de socialização, mostrando-se um tema recorrente do seu jogar presente nas suas diversas atividades cotidianas. O Corcundinha simboliza o esvaziamento do $e u$, as relações de autodistanciamento que ocorrem mimeticamente por meio do jogar na infância; ele representa a possibilidade de ser sujeito e, portanto, do desenvolvimento do self ${ }^{6}$

${ }^{6}$ A imagem "O Corcundinha" é usualmente interpretada do ponto de vista do Benjamin adulto rememorando sua infância, como
Sempre que Benjamin, ao jogar, se distanciava de seu $e u$, deparava-se, assim como o pintor chinês dentro de seu quadro, com a porta que conduz à possibilidade do reconhecimento de uma imagem de si, o caminho que conduz ao âmago de seu self. "Aquele que é olhado pelo Corcundinha não sabe prestar atenção. Nem a si mesmo nem ao Corcundinha". Isto é, aquele que é olhado pelo Corcundinha distancia-se de seu eu. "Encontra-se sobressaltado em frente a uma pilha de cacos: 'Quando a sopinha quero tomar / É à cozinha que vou / Lá encontro um Corcundinha / Que minha tigela quebrou"' ([1932-1933] Benjamin, 1987, p. 142).

A pilha de cacos da tigela quebrada pelo Corcundinha pode ser compreendida como o conjunto das imagens que aparecem no texto "Infância em Berlim...”, são instantes da infância capturados, são “uma série finita de imagens exemplares, mônadas (para usarmos um dos seus conceitos preferidos) privilegiadas que retêm a extensão do tempo na intensidade de uma vibração, de um relâmpago, do Kairos" (Gagnebin, 1994, p. 91). São as imagens que, vistas como um todo, representam o self que é formado na infância. ${ }^{7}$

Assim como o Benjamin criança encontrava-se frequentemente distanciado de si, assemelhando-se aos objetos, às pessoas e aos animais ao seu redor, podemos pensar no Corcundinha e na Mummerehlen como sendo representantes desse estar fora de si. Onde quer que o Corcundinha estivesse, o eu não estava, o Corcundinha estava sempre perante o eu. Do mesmo modo como o jogar sempre acompanha

em Stüssi (1977). Diferentemente desse enfoque, proponho que "O Corcundinha" seja analisado tendo em vista seus significados na construção do self na infância, e não na vida adulta.

7 Para o Benjamin adulto, ao rememorar sua infância, o Corcundinha, que foi quem quebrou a tigela, é o representante "do fracasso e do esquecimento"; mas, ao mesmo tempo, é quem apresenta a Benjamin os cacos, as imagens, pois ele é também "o autor das imagens da lembrança”. Assim como em "A Mummerehlen”, aqui também aparece a imagem do prato de sopa, que, quando escavado, revela por um instante o que está no fundo, para logo a seguir ser coberto novamente pela sopa. 
a criança, o Corcundinha o acompanhava, tomando parte nesse jogar.

\begin{abstract}
Onde quer que ele aparecesse, eu ficava a ver navios. [onde quer que ele aparecesse, o "eu" esvaziava-se] Pois as coisas se subtraíam até que, depois de anos, o jardim se transformasse num jardinete, o quarto num quartinho, o banco numa banqueta. Encolhiam-se, e era como se crescesse nelas uma corcova que, por muito tempo, deixava-as incorporadas ao mundo do homenzinho. Andava sempre à minha frente em toda parte. Solícito, colocava-se no caminho. Fora isso, nada me fazia, esse procurador cinzento, senão recolher a meias de qualquer coisa que eu tocasse o esquecimento. "Quando ao meu quartinho vou / Meu mingauzinho provar/Lá descubro o Corcundinha / Que metade quer tomar". Assim encontrava o homenzinho frequentemente. Só que nunca o vi. Só ele me via. E tanto mais nítido quanto menos eu me via a mim mesmo. (Benjamin, [1932-1933] 1987, p. 142)
\end{abstract}

Nem a Mummerehlen nem o Corcundinha eram vistos pela criança; já o Corcundinha encontrava-se nos porões, nos subterrâneos, nas adegas e observava o Benjamin criança por entre as frestas, aberturas, ou então nos sonhos noturnos.

Benjamin afirma encontrar amiúde o Corcundinha, mas nunca o ter visto, pois, assim como a Mummerehlen, ele o encontrava no jogar, no jogar com as rimas, no mundo da fantasia infantil que permeava os passeios pela cidade de Berlim, ao observar os porões, ao comer o mingau. Atividades corriqueiras e cotidianas, mas que, na infância, eram executadas na forma de jogo. Ele os encontrava no jogar, mas não os via, pois o sentido do jogo era exatamente esse, ser visto e não ver; pois aqueles veem encontram-se mascarados, obscuros, ocultos. O que Benjamin encontrava eram os vestígios da passagem do Corcundinha e da Mummerehlen: os cacos de vidro, os flocos de neve, as tintas, as nuvens e, sobretudo, os olhares, olhos que o observavam mas que nunca encontravam o seu olhar.

Entretanto, o Corcundinha e a Mummerehlen não devem ser considerados apenas seres fantásticos. São representantes do mundo "deturpado" da infância; são também os autores das imagens da lembrança. Representam a imagem do self que surge toda vez que o eu é esvaziado. Esse eu que é esvaziado (o eu manequim) nunca pode ver o self que emerge, pois é exatamente esse sair de si que permite o seu surgimento. O self que emerge no jogar situa-se em uma temporalidade singular, que não está nem no passado, nem no presente. E é capaz de olhar para o passado não tal como ele realmente foi, e para o presente não tal como ele realmente é; ele olha o passado e o presente dessa perspectiva temporal distinta. E é essa temporalidade singular que permite olhar o passado na forma de imagens, e captar, em um instante, a imagem de si.

Para o Benjamin adulto, o Corcundinha pode ser considerado uma ponte do mundo adulto com o mundo da criança, e a própria imagem do Corcundinha o revela. Um homem adulto, só que com o tamanho de uma criança. Ele é os olhos da pessoa que vê sua própria infância por meio de imagens - não como nas autobiografias usuais, voluntariamente em busca da memória, mas de forma espontânea, evocando o jogar. E a corcova que o achata representa todo o peso das imagens da infância. O Corcundinha subtrai à criança as suas experiências inconscientes e as retém; dessa forma prepara o rememorar.

E assim termina "O Corcundinha":

Penso que isso de "toda vida", que dizem passar diante dos olhos do moribundo, se compõe de tais imagens que tem de nós o homenzinho. Passam a jato como as folhas dos livrinhos de encadernação rija, precursores de nossos cinematógrafos. Com um leve pressionar, o polegar se movia ao longo da superfície de corte; então se viam imagens que duravam segundos e que mal se distinguiam umas das outras. Em seu decurso fugaz deixavam entrever o boxeador em ação e o nadador lutando contra as ondas. O homenzinho tem também imagens de mim. Viu-me nos esconderijos, de fronte da jaula da lontra, na manhã de inverno, junto ao telefone no corredor, no Brauhausberg com as borboletas e em minha pista de patinação com a música da charanga, em frente da caixa de costura e debruçado sob minha gaveta, na Blumeshof e quando estava doente e acamado, em Glienicke e na estação ferroviária. Contudo, sua voz, que faz lembrar 
o zumbido da chama de gás, me cochicha para além do limiar do século: "Por favor, eu te peço, criancinha / Que reze também pelo Corcundinha”. (Benjamin, [1932-1933] 1987, p. 142)

Esse $e u$ esvaziado passou a conter as imagens, como cacos, fragmentos embaralhados e imiscuídos uns nos outros, que apareciam e desapareciam com a rapidez de um relâmpago. Imagens que falavam baixinho, como o zumbido da concha vazia que vem lá de longe, e que dão as pistas de um caminho que conduz à possibilidade de ser um sujeito e de se colocar no mundo de forma singular. Possibilidade essa que aparece tão clara na infância, no jogar, com o exercício da faculdade mimética. Os objetos, as pessoas, os animais e os demais elementos do mundo social olham de volta para a criança como em um círculo traçado pelos processos miméticos, e então a criança pode desenvolver seu self e sua consciência do self; são as semelhanças que permitem a familiaridade com o mundo e sua inserção nele, sua socialização (Gebauer \& Wulf, 1998, p. 7-21).

\section{Considerações finais}

As análises das duas imagens do rememorar da infância de Benjamin demostram que, nos processos de socialização infantil, as crianças descobrem paulatinamente os significados sociais dos elementos ao seu redor. Em um primeiro momento, muitos objetos/personagens da vida cotidiana não possuem sentido para elas. Cabe às crianças, assemelhando-se ao mundo circundante, na forma de jogo, procurar “descobrir" esses significados, isto é, criar significados. Os processos de socialização são constituídos por essas descobertas, nas quais os objetos e as pessoas do mundo social adquirem sentido. Pensar na busca desses sentidos é pensar também na busca da imagem de si nas crianças, a busca de uma identidade que tome parte nesse mundo social, o desenvolvimento de um self individual. No jogo, o eu infantil é constantemente esvaziado ao se assemelhar o tempo todo àquilo que está fora dele, pois o que permite à criança construir o seu self é o ato de esvaziar o próprio $e u$, por meio do jogar, como distanciamento. $\mathrm{O}$ assemelhar-se ao mundo circundante de Benjamin, isto é, o exercício da faculdade mimética na infância, corresponderia, nesse sentido, ao assumir o papel do outro de Mead, fundamentais para o desenvolvimento do self por meio do jogar.

As ações de jogo são ações que fortalecem o indivíduo enquanto ser autônomo e, ao mesmo tempo, fortalecem suas relações com a sociedade e com os outros indivíduos (nesse sentido, criam a sociedade, socializam). Nessas ações sociais específicas, o outro representa um papel fundamental - ele funciona como um espelho de nós mesmos, mas também, ao mesmo tempo, cria um saber da diferença -, é aquilo que é próprio e aquilo que é estranho (o eu e o outro) (Gebauer \& Wulf, 1998, p. 18). O princípio do jogo não é a redução a um singular; com efeito, em vez de observar o jogo da perspectiva do indivíduo (seus desenvolvimentos cognitivos individuais), devemos, de uma perspectiva sociológica, observálo como uma forma específica de processo que, em um mundo mimeticamente produzido, relaciona indivíduo e processos de socialização. Desse ponto de vista, o jogo, como uma ação mimética, apresenta-se como esfera intermediária entre realidade interna e externa (Winnicott, 1971), realidades que não devem ser tratadas como se estivessem separadas, mas em relação constante e interdependente. O jogo volve o indivíduo para fora de si (Benjamin, [1932-1933] 1987), pois o jogador recebe o acontecimento não apenas dentro de si mesmo, mas como um acontecimento corpóreo entre os seres humanos (Gebauer \& Wulf, 1998, p. 18).

A mimese permite que as crianças que jogam não apenas construam o seu próprio mundo de jogo de maneira criativa, como também contribuam criativamente para o mundo social. Em meio a processos miméticos, ao jogar, elas agem com criatividade nesses dois mundos ao mesmo tempo. Desse modo, os processos miméticos no jogo infantil perpassam tanto a apropriação de elementos do mundo adulto como a transformação deles em jogo; e a contribuição desses 
elementos ressemantizados pelo jogo, para o mundo e cultura adultos (Corsaro, 1997). "Rua de mão dupla, a mímesis não só tira do mundo mas lhe entrega algo que ele não tinha" (Lima, 2000, p. 328).

Assim como o jogar é permeado por processos miméticos, os processos de socialização também o são, e é por isso que "socialização pode ser entendida como uma série de processos abertos em todas as idades e no que concerne aos seus resultados, por meio dos quais os indivíduos formam 'tensões ativas' com o seu ambiente" (Liegle, 1991, p. 215); essas tensões ativas são os próprios processos miméticos em ação. Dessa forma, os processos miméticos estão presentes tanto no jogo, incorporando mimeticamente elementos do mundo social, como no indivíduo, que, ao se socializar, incorpora mimeticamente elementos do mundo social, assim como o mundo social incorpora, por sua vez, elementos do ser individual e do jogo em suas dinâmicas próprias. Todas essas três dimensões estão relacionadas: self individual, jogo e mundo social; o que as correlaciona são os processos miméticos. Desse modo, as crianças tornam-se, no jogo, parte de um todo maior, de uma riquíssima rede de relações e interdependências, e é assim que elas, ao mesmo tempo, constroem suas identidades, o seu self individual.

\section{Referências bibliográficas}

BATESON, Gregory. Steps to an Ecology of mind. Chicago: The University of Chicago Press, 2000.

BENJAMIN, Walter. A doutrina das semelhanças [1933]. A imagem de Proust [1929]. O narrador [1936]. In: BENJAMIN, Walter. Obras Escolhidas I - magia e técnica, arte e política. São Paulo: Brasiliense, 1985.

. Infância em Berlim por volta de 1900 [1932-1933]. São Paulo: Brasiliense, 1987.

Reflexões: a criança, o brinquedo, a educação. [19131932]. São Paulo: Duas Cidades e Editora 34, 2002.

BROUGÈRE, Gilles E. Brinquedo e cultura. São Paulo: Cortez, 1995.

Jogo e educação. Porto Alegre: Artes Médicas, 1999.

. Brinquedo e companhia. São Paulo: Cortez, 2004.
CAILLOIS, Roger. Les jeux et les hommes [1950]. La masque et le vertige. Paris: Gallimard, 1967.

CORSARO, William. The sociology of childhood. Thousand Oaks: Pine Forge Press, 1997.

ELIAS, Norbert. Was ist Soziologie? [1970]. Weinheim und München: Juventa, 1993.

FASS, Paula S. Encyclopedia of children and childhood in history and society. New York: MacMillan, 2003.

FINK, Eugen. Spiel als Weltsymbol. Stuttgart: W. Kohlhammer, 1960.

FLITNER, Andreas (Org.). Das Kinderspiel. [1973] 4. Aufl., München: Piper, 1998.

FRÖBEL, Friedrich W. A. A educação do homem [1891]. Passo Fundo: UPF, 2001.

GAGNEBIN, Jeanne Marie. História e narração em W. Benjamin. São Paulo: Perspectiva, 1994.

GEBAUER, Gunter; WULF, Cristoph. Mimesis. Kultur, Kunst, Gesellschaft. Hamburg: Rowohlts, 1992.

Spiel, Ritual, Geste. Mimetisches Handeln in der sozialen Welt. Hamburg: Rowohlts, 1998.

GEERTZ, Clifford. Interpretação das culturas. Rio de Janeiro: Zahar, 1978.

GOLDMAN, Laurence R. Child's play: myth, mimesis and makebelive. New York: Oxford University Press, 1998.

GRIGOROWITSCHS, Tamara. O conceito "socialização" caiu em desuso? Uma análise dos processos de socialização na infância com base em Georg Simmel e George H. Mead. Educação e Sociedade, v. 29, n. 102, p. 33-54, jan./abr. 2008.

GROSS, Karl. Die Spiele der Menschen. Jena: FISCHER, 1895. HUIZINGA, Johan. Homo ludens. O jogo como elemento da cultura [1938]. São Paulo: Perspectiva, 1973.

LIEGLE, Ludwig. Kulturvergleichende Ansätze in der Sozialisationsforschung. In: HURRELMANN, Klaus; ULICH Dieter (Orgs.). Neues Handbuch der Sozializationsforschung. Weinheim und Basel: Beltz, 1991.

LIMA, Luiz Costa. Mímesis: desafio ao pensamento. Rio de Janeiro: Civilização Brasileira, 2000.

MCCARTHY, Dougle; DAS, Robin. The cognitive and emotional significance of play in child development. George Herbert Mead and Donald W. Winnicott. In: HAMILTON, Peter. George H. Mead. Critical assessments. London: Routledge, v. 4, p. 239-256, 1992. MEAD, George Herbert. Mind, self and society [1934]. Chicago: The University of Chicago Press, 1952.

OPITZ, Michael. Ähnlichkeit. In: OPITZ, Michael; WIZISLA, Er- 
dmut (Orgs.). Benjamins Begriffe. Frankfurt am Main: Suhrkamp, 2000.

PLESSNER, Helmuth. Ausdruck und menschliche Natur [1941]. Frankfurt am Main: Suhrkamp, 2003. p. 201-387.

POPITZ, Heinrich. Wege der Kreativität. 2. ed. Aufl., Tübingen: Mohr Siebeck, 2000.

ROUSSEAU, Jean-Jacques. Émile ou de l'éducation [1762]. Paris: Flammarion, 1966.

RUNKEL, Gunter. Soziologie des Spiels. Frankfurt am Main: Hain, 1986.

SCHERR, Albert. Sozialisation, Person, Individuum. In: SCHÄFERS, Bernhard (Orgs.). Einführung in Hauptbegriffe der Soziologie. 6. e. Aufl., Opladen: Leske und Budrich, 2002. p. 45-66

SCHEUERL, Hans. Theorien des Spiels [1955]. 10. Aufl., Weinheim und Basel: Beltz, 1975.

SCHILLER, Friedrich von. Über die ästhetische Erziehung des Menschen in eine Reihe von Briefen [1795]. In: Sämtlichen Werke. München: Carl Hanser, 1993.

SIMMEL, Georg. Grundfragen der Soziologie [1917]. Berlim, New York: Walter de Gruyter, 1984.

. Soziologie. Untersuchungen über die Formen der Vergesellschaftung [1908]. Gesamtausgabe. Band 11. Frankfurt am Main: Suhrkamp, 1992.

STÜSSI, Anna. Erinnerung an die Zukunft. Walter Benjamins "Berliner Kindheit um Neunzehnhundert". Göttingen: Vandenhoeck \& Ruprecht, 1977.

SUTTON-SMITH, Brian. Dialetik des Spiels. Eine Theorie des Spiels, der Spiele und des Sports. Schorndorf: Karl Hoffmann, 1978.
THORNE, Barrie. Gender Play. Girls and Boys in School. New Brunswick: Rutgers University Press, 1993.

WAIZBORT, Leopoldo. Elias e Simmel. In: WAIZBORT, Leopoldo (org.). Dossiê Norbert Elias. São Paulo: Edusp, 2000.

WINNICOTT, Donald W. Playing and reality. Norfolk: Tavistock, 1971.

WULF, Christoph (org.). Vom Menschen. Handbuch historische Anthropologie. Weinheim und Basel: Beltz, 1997.

TAMARA GRIGOROWITSCHS, mestre em sociologia da educação pela Universidade de São Paulo (USP), é doutoranda no Programa de Pós-Graduação em Sociologia na mesma universidade. Publicações recentes: O conceito "socialização" caiu em desuso? Uma análise dos processos de socialização na infância com base em Georg Simmel e George H. Mead (Educação \& Sociedade, v.29, n. 102, p. 33-54, jan./abr. 2008); em co-autoria com SANTOS, Lilian Piorkowsky, Jogos infantis e garotas indisciplinadas: dois estudos de gênero (Revista Educação. Grandes Temas 2 - Gênero e Sexualidade: Mapeando as igualdades e as diferenças entre os sexos e suas relações com a educação. São Paulo: Segmentos, p. 76-83, mar. 2008.); Jogo, processos de socialização e mimese. Uma análise sociológica do jogar infantil coletivo no recreio escolar e suas relações de gênero (São Paulo: Alameda Editorial, no prelo). Pesquisa em desenvolvimento: "Sociologia, história e sociologia histórica: uma análise dos escritos de Max Weber sobre a Antiguidade”.E-mail: tgrigoro@yahoo.com.br

Recebido em março de 2009 Aprovado em abril de 2010 


\section{Resumos/Abstracts/Resumens}

Irán Guerrero e Judith Kalman

\section{A inserção da tecnologia em aula: estabilidade e processos instituintes na prática docente}

Nos últimos anos foi enfatizado o uso da tecnologia em escolas mexicanas, a fim de modificar práticas correntes em sala de aula. No entanto, mesmo quando os professores adotam inovações tecnológicas, práticas antigas são mantidas. Poucos estudos documentam empiricamente esta estabilidade. Neste artigo, pretende-se mostrar evidências desta permanência e variações surgidas quando a tecnologia é utilizada em aula. Para isso, analisamos o caso de um professor que usa o computador para trabalhar um tema de geografia com alunos do ensino médio. Pretendemos identificar as interações promovidas pelo uso dessa tecnologia, as formas de participação dos estudantes, assim como a estabilidade e as mudanças nas práticas, com o objetivo de contribuir para a discussão sobre o uso da tecnologia na escola e mostrar que, mais que um recurso didático para transmitir informações, o computador é um instrumento sociocultural com potencialidade para construir significados.

Palavras-claves: tecnologia; prática docente; interações

The use of technology in the classroom: stability and institutive processes in teacher's practice

In recent years the use of technology in Mexican schools to modify current practice in classrooms has been emphasized. Even when teachers adopt technological innovations practices are maintained rather than transformed. Few studies document empirically the said stability. This text intends to reveal evidence of the permanence and variations which arise when technology is used in the classroom. To that end, we analyse the case of a teacher who uses the computer to develop the theme of Geography with secondary school students. We intend to identify the interactions which promote this use of technology, the students'forms of participation and the stability and change in practices, with the objective of contributing to the discussion on technology in schools and to show that the computer is more than a didactic resource for transmitting information. It is a socio-cultural artefact with potential for constructing meaning.

Key words: technology, teacher practice, interactions

La inserción de la tecnología en el aula: estabilidad y procesos instituyentes en la práctica docente

En los años recientes se ha enfatizado el uso de tecnología en escuelas mexicanas para modificar prácticas recurrentes en las aulas. Aún cuando los docentes adoptan innovaciones tecnológicas, las prácticas se mantienen (Bruce y Hogan, 1998; Cuban, 1993) más que transformarse. Pocos estudios documentan empiricamente dicha estabilidad; este trabajo pretende mostrar evidencias de la permanencia y variaciones que surgen cuando se utiliza la tecnología en el aula. Para ello, analizamos el caso de un docente que usa la computadora para trabajar un tema de geografía con alumnos de secundaria. Pretendemos identificar las interacciones que promueve este uso de tecnología, las formas de participación de los estudiantes y la estabilidady cambio en las prácticas, con el fin de contribuir a la discusión sobre tecnología en la escuela y mostrar que la computadora es más que un recurso didáctico para transmitir información, es un artefacto sociocultural con potencialidades para construir significados.

Palavras claves: tecnología; práctica docente; interacciones

Tamara Grigorowitschs

Jogo, mimese e infância; o papel do jogar infantil nos processos de construção do self

$\mathrm{O}$ artigo aborda, de uma perspectiva sociológica, o papel do jogo nos processos de socialização infantil e de formação do self na infância, lançando mão de autores clássicos como Walter Benjamin e George Herbert Mead e de alguns de seus intérpretes contemporâneos, como Gunter Gebauer e Christoph Wulf, autores que organizaram essa discussão em torno do conceito de mimese.

Apresenta também uma análise de duas “imagens" presentes em Infância em Berlim por volta de 1900 , de autoria 
de Walter Benjamin, que retratam, de forma autobiográfica, o papel do jogo para a formação do self na infância.

Palavras-chave: Jogo, brincadeira, mimese, identidade, socialização, infância

Games, mimesis and childhood: the role of children's play in the development of self

This paper presents a sociological analysis of the influence of children's play on socialization processes and on the development of self in childhood, making use of classical authors like Walter Benjamin and George Herbert Mead and some of their contemporary interpreters like Gunter Gebauer and Christoph Wulf, all of whom organised this discussion around the concept of mimesis. In the second part, it analyses two "images" present in Childhood in Berlin around 1900, by Walter Benjamin, which portrays the role of children's play in the development of self in childhood from an autobiographical perspective.

Key words: play, game, mimesis, identity, socialization, childhood

Juego, mimesis e infancia: el papel de jugar en los procesos de construcción del self

El artículo aborda, desde una perspectiva sociológica, el papel del juego en los procesos de socialización infantil y de la formación del self en la infancia, recurriendo a autores clásicos como Walter Benjamin y Georg Herbert Meady de algunos de sus intérpretes contemporáneos, como Gunter Gebauer y Christoph Wulf, autores que organizaron esa discusión en torno del concepto de mimesis. Presenta también un análisis de dos "imágenes" presentes en La infancia en Berlín alrededor de 1900, de autoría de Walter Benjamin, que retratan de forma autobiográfica el papel del juego para la formación del self en la infancia.

Palabras clave: Juego, diversión, mimesis, identidad, socialización, infancia
Ana Flávia Lopes Magela Gerhardt

Integração conceptual, formação de conceitos e aprendizado

Com base nas premissas postas pelo psicólogo russo Lev Vygotsky acerca do desenvolvimento cognitivo, discutemse dois fatos geralmente apontados por pesquisas em educação que focalizam as formas de organização conceptual por parte dos alunos: a articulação de conceitos e o descolamento da realidade imediata, a fim de definir seu estatuto de epifenômenos decorrentes da aquisição de novos conceitos, dado que ambas as operações focalizam organizações de conceitos que resultam do processo do aprendizado, e não o que de fato ocorre na mente dos alunos no momento em que aprendem. Propõe-se assumir os pressupostos da psicologia cognitiva contemporânea que permitem reconhecer o momento de aprender como um processo de mesclagem ou integração conceptual ou, mais especificamente, doublescope blending, descrevendo as suas características particulares em relação ao trato com os conceitos em sala de aula, bem como aos participantes do processo de aprendizado na escola. Palavras-chave: psicologia cognitiva; integração conceptual; Lev Vygotsky; desenvolvimento cognitivo; escolarização; aprendizado

\section{Conceptual integration, concept formation and learning}

Based on the premises established by the Russian psychologist Lev Vygotsky concerning cognitive development, we discuss two facts generally indicated by educational research which focus on the forms of conceptual organization by students: the articulation of concepts and their detachment from immediate reality, in order to define their status as epiphenomena related to the acquisition of new concepts, since both cognitive operations focus on the organization of concepts which result from the process of learning, and not on what really happens in the students' minds at the moment they learn. We propose to take the assumptions of contemporary Cognitive Psychology that allow us to recognize the moment of learning as a process of mixing or conceptual integration or, more specifically, double-scope blending, describing its particular characteristics in relation to handling concepts in the classroom as well as to the participants of the learning process in school.

Key words: cognitive psychology; conceptual integration; Lev Vygotsky; cognitive development; schooling; learning

Integración conceptual, formación de conceptos y aprendizaje

A partir de las premisas puestas por el psicólogo ruso Lev Vygotsky a respecto del desarrollo cognitivo, se discuten dos hechos generalmente apuntados por encuestas en Educación que focalizan las formas de organización conceptual por parte de alumnos: la articulación de conceptos y la desunión de la realidad inmediata, con el fin de definir su estatuto de epifenómenos consecuentes de la adquisición de nuevos conceptos, dado que ambas operaciones enfocan organizaciones de conceptos que resultan del proceso del aprendizaje, y no lo que de hecho ocurre en la mente de los alumnos en el momento en que aprenden. Se propone asumir los preceptos de la Psicología Cognitiva contemporánea que permiten reconocer el momento de aprender como un proceso de mezcla o integración conceptual o, más especificamente, doublescope blending, describiendo sus características particulares en relación al tratamiento con los conceptos en clase, bien como a los participantes del proceso de aprendizaje en la escuela. Palabras clave: psicología cognitiva; integración conceptual; Lev Vygotsky; desarrollo cognitivo; escolaridad; aprendizaje 